\title{
Prevalence and Antibiotic Susceptibility of Listeria Monocytogenes Isolated from Retail Ready-to-Eat Meat Products in Gorgan, Iran
}

\author{
Vaez Nemati $^{*}{ }^{1}$, Morteza Khomeiri ${ }^{1}$, Alireza Sadeghi Mahoonak ${ }^{1}$, Ali Moayedi ${ }^{1}$ \\ 1- Department of Food Science and Technology, Gorgan University of Agricultural Sciences and Natural Resources, Gorgan, Iran.
}

\section{A B S T R A C T}

Background and Objectives: Listeria monocytogenes are known as an emerged foodborne pathogen and considered as a severe health risk. In the present study, prevalence and antibiotic resistance of L. monocytogenes isolated from readyto-eat meat products in Iran were assessed.

Materials and Methods: A total of 200 ready-to-eat meat products, including chicken meat (wing, breast, and leg), lamb and fish, were collected, and L. monocytogenes was isolated according to ISO 11290-1. All of the isolates were verified using polymerase chain reaction and serotyping methods. Antibiotics susceptibility of L. monocytogenes isolates was assessed using the broth microdilution method.

Results: The presence of $L$. monocytogenes was verified in $13 \%$ of the samples. The presence of $L$. monocytogenes was reported in $26 \%$ of roast chicken meat, $5 \%$ of roast fish and $8.33 \%$ of cooked beef. Serology showed that Serotype 1/2a $(48.13 \%)$ was the dominant serotype, followed by $4 \mathrm{~b}(38.4 \%), 1 / 2 \mathrm{c}(6.99 \%)$ and $1 / 2 \mathrm{~b}(6.48 \%)$. The result showed that 37 out of $100 \mathrm{~L}$. monocytogenes isolates were resistant to all tested antibiotics. Furthermore, eight isolates were intermediately multi-resistant to the antibiotics. The rate of antibiotic resistance in L. monocytogenes was $52 \%$ in Serotype 1/2a, 39\% in Serotype 4b, and 35\% in Serotype 1/2c. Isolates of L. monocytogenes were mostly resistant to penicillin, ampicillin and erythromycin, but highly susceptible to tetracycline and gentamycin.

Conclusions: The high level of L. monocytogenes prevalence and its resistance to antibacterial agents in meat products may result in severe human listeriosis. Therefore, it is necessary to use efficient monitoring protocols for antibiotic administration and further safety management systems in food production units.

Keywords: Listeria monocytogenes, Lamb, Chicken, Antibiotic, Fish

\section{Introduction}

Listeria monocytogenes, the agent of listeriosis, is a food-borne pathogen that can cause fatal health problems, especially in immunocompromised patients. The L. monocytogenes infections are associated with mortality rates of nearly $12 \%$, which is the highest rate within foodborne pathogens (1). This pathogen is found in soil and water as well as infected animals. In general, L. monocytogenes is transmitted to humans through contaminated foods (2). The bacterial strains differ in their epidemic potentials and serotypes as Serotypes $4 \mathrm{~b}, 1 / 2 \mathrm{a}$ and $1 / 2 \mathrm{~b}$ are responsible for nearly $90 \%$ of the human listeriosis (3). other abilities of L. monocytogenes are linked to the formation of biofilms, which can grow at refrigerator temperatures and high concentration tolerances to $\mathrm{NaCl}$ (4). Several studies reported $L$. monocytogenes from meat products $(5,6)$. The prevalence of $L$. monocytogenes in ready-to-eat (RTE) meat products mostly ranged from 2.60 to $28 \%$ in other studies (7-10). Moreover, the contamination rate is different, affected by the food type and geographical area. Naturally, L. monocytogenes is sensitive to a wide range of antibiotics (2). For several years, the resistance rate of $L$. monocytogenes to antibiotics was constant (2). Nevertheless, new reports suggest increases in antibiotic resistance of the bacteria isolated from foods such as dairy products and meats $(11,12)$. In the present study, the 
prevalence of L. monocytogenes isolates from RTE meats such as chicken meat (wing, breast and leg), lamb and smoked fish was assessed to report their genetic affiliation and antibiotic susceptibility using serological typing methods.

\section{Materials and Methods}

\section{Collection of the L. monocytogenes isolates}

A total of 200 RTE meat product samples were collected from 40 restaurants and retail supermarkets in Gorgan, Iran, from September to November 2018. These samples were transported to the Microbiology Laboratory at Gorgan University of Agricultural Science and Natural Resources under appropriate conditions. Samples were analyzed for $L$. monocytogenes, according to ISO 11290-1 (13). Briefly, $25 \mathrm{~g}$ of each sample was homogenized with $225 \mathrm{ml}$ of Listeria enrichment broth and incubated at $37^{\circ} \mathrm{C}$ for $24 \mathrm{~h}$. Then $0.1 \mathrm{~mL}$ of pre-enrichment media was added into the CHROM agar Listeria and incubated for $24 \mathrm{~h}$ at $37{ }^{\circ} \mathrm{C}$. Four suspicious Listeria colonies were chosen from every selected agar, and then secondary enrichments were streaked into a new CHROM agar and then incubated for $24 \mathrm{~h}$ at $37^{\circ} \mathrm{C}$. Confirmation tests were performed using pure culture obtained from BHI (Merck, Germany) agar. Several biochemical tests were used for confirmation, including Gram staining, blood agar test, qualifying the consumption of rhamnose and xylose and mannitol.

\section{Extraction of DNA from the $L$. monocytogenes isolates}

In the following, the genomic DNAs were separated from $1 \mathrm{~mL}$ of the tested bacterial culture mediums, using a "Bacterial Genomic DNA Purification Kit" (DENA Zist Asia, Iran). DNA

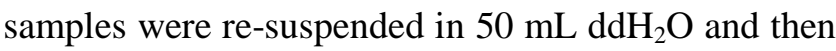
were stored at $-20 \mathrm{C}$.

\section{Polymerase chain reaction (PCR) assay}

The PCR reactions were proceeded under optimized conditions using L. monocytogenes PTCC 1298 as control. The PCR was carried out in a $25-\mu 1$ volume of the mixture containing ten $\mathrm{mM}$ of tris$\mathrm{HCl}, 50 \mathrm{mM}$ of $\mathrm{KCl}, 1.5 \mathrm{mM}$ of $\mathrm{MgCl}_{2}, 0.21 \mathrm{M}$ of each primer, $0.2 \mathrm{mM}$ of each dNTP, $1 \mu \mathrm{l}$ of DNA template and 0.5 unit of Taq polymerase (Takara, Japan). The forward primer included 5'-
TTGCGCAACAAACTGAAGC- $3^{\prime}$ and the reverse primer included 5'-GCTTTTACGAGAGCACCTGG$3 '$. The PCR condition respectively included 35 cycles of denaturation, annealing and extension at $95{ }^{\circ} \mathrm{C}$ for $30 \mathrm{~s}, 56{ }^{\mathrm{c}} \mathrm{C}$ for $30 \mathrm{~s}$ and $72{ }^{\mathrm{C}} \mathrm{C}$ for $1 \mathrm{~min}$. The final extension was carried out at $72{ }^{\circ} \mathrm{C}$ for $7 \mathrm{~min}$. The PCR products were electrophoresed to verify expected bands of $346 \mathrm{bp}$ (5).

\section{Serotyping of the $L$. monocytogenes isolates}

All of the isolates were serotyped based on a protocol by Seeliger and Hohne (14). The isolates were analyzed using Listeria SEIKEN Antisera Kit (set code: 294616) for $\mathrm{O}$ and $\mathrm{H}$ antigens according to the kit manufacturer's instruction (Denka-Seiken, Japan).

\section{Antibiotic resistance of the $L$. monocytogenes isolates}

Antibiotics susceptibility of the L. monocytogenes isolates was assessed using the broth microdilution method (15). The antibiotics included enrofloxacin (5 $\mu \mathrm{g})$, ciprofloxacin $(5 \mu \mathrm{g})$, ampicillin $(10 \mu \mathrm{g})$, erythromycin $(15 \mu \mathrm{g})$, penicillin $(5 \mu \mathrm{g})$, clindamycin $(2 \mu \mathrm{g})$, tetracycline $(30 \mu \mathrm{g})$, gentamycin $(10 \mu \mathrm{g})$ and vancomycin $(30 \mu \mathrm{g})$. The minimum inhibitory concentration (MIC) was calculated using broth microdilution susceptibility and serial microdilution assays using Sensititre Vizion System (Trek, UK). Antibiotic susceptibility of the isolates was assessed according to instructions by the Clinical and Laboratory Standards Institute (CLSI) (16).

\section{Statistical analysis}

Rates of L. monocytogenes contamination in various RTE meat products were compared with each other using the chi-square test of the SPSS Software v.9.0 (SPSS Inc., Chicago, IL, USA). Furthermore, distributions of various serotypes of $L$. monocytogenes in each season were compared with each other using the same test. Differences were considered significant at $P<0.05$.

\section{Results}

\section{Prevalence and serotype distribution of the $L$. monocytogenes isolates in RTE meat products}

From a total of 200 RTE meat product samples, 29 samples $(14.5 \%)$ were contaminated with $L$. monocytogenes (Table 1). Roasted chicken meats included the highest $L$. monocytogenes contamination 
rate with 13 (26\%) out of 50 positive samples. Moreover, $5 \%$ of the roasted fish and $8.33 \%$ of the cocked beef were contaminated. Results of the serology showed that Serotype 1/2a was the most common serotype (45.4\%) in the present study, majorly similar to other studies (17-19), followed by Serotypes 4b (38.4\%), 1/2c (6.99\%) and 1/2b $(6.58 \%)$.

Table 1. Prevalence of Listeria monocytogenes in RTE meat products collected from retail markets in Iran

\begin{tabular}{lll}
\hline Sample & Food item & L. monocytogenes (\%) \\
\hline 1 & Cooked beef & $8.33(5 / 60)$ \\
2 & Roast chicken & $26.25(21 / 80)$ \\
3 & Roast fish & $5(3 / 60)$ \\
\hline
\end{tabular}

\section{Antibiotic susceptibility}

A total of $100 \mathrm{~L}$. monocytogenes isolated from RTE meat products were tested for resistance against nine antibiotics (Table 2). Results showed that 37 isolates (37\%) were resistant to all antibiotics. Moreover, all isolates were resistant to at least one (40\%), two (18.3\%), three (12.4\%), four $(4.20 \%)$ or five $(3.25 \%)$ antibiotics. The bacterial resistance to ampicillin $(64.71 \%)$ was the most common finding. Resistances to erythromycin, vancomycin, enrofloxacin, and ciprofloxacin were detected in $52.94,35.29,29.41$ and $16.64 \%$ of the $L$. monocytogenes isolate, respectively (Table 2 ). The $L$. monocytogenes Serotypes 1/2a was the most common serotype in the present study, mostly resistant to ampicillin, penicillin and tetracycline. Serotype $4 b$ was mostly resistant to vancomycin and penicillin, Serotype $1 / 2 b$ to erythromycin and penicillin and Serotype $1 / 2 \mathrm{c}$ to ampicillin (Table 2 ).

Table 2. Number and proportion of the Listeria monocytogenes isolates resistant to nine antimicrobial agents

\begin{tabular}{|c|c|c|c|c|c|}
\hline \multirow[t]{2}{*}{ Antimicrobial agent } & \multicolumn{4}{|c|}{ L. monocytogenes $(n=100)$} & \multirow[t]{2}{*}{ Total no. (\%) } \\
\hline & 1/2a no. (\%) & 1/2b no. (\%) & 1/2c no. (\%) & 4b no. (\%) & \\
\hline Vancomycin & $26(27.4)$ & $0(0.0)$ & $8(16.66)$ & $1(18.8)$ & $35(35)$ \\
\hline Ampicillin & $43(39)$ & $12(9.09)$ & $7(18.18)$ & $2(18.18)$ & $64(64)$ \\
\hline Erythromycin & $41(37.8)$ & $8(8)$ & $1(11.11)$ & $2(22.22)$ & $52(52.94)$ \\
\hline Enrofloxacin & $13(8.2)$ & $0(0.0)$ & $2(20)$ & $3(20)$ & $18(29.41)$ \\
\hline Ciprofloxacin & $2(1.91)$ & $0(0.0)$ & $0(0.0)$ & $1(33.33)$ & $3(16.64)$ \\
\hline Tetracycline & $1(0.96)$ & $0(0.0)$ & $0(0.0)$ & $3(54.3)$ & $4(5.78)$ \\
\hline Penicillin & $5(4.83)$ & $6(20)$ & $0(0.0)$ & $3(30)$ & $14(58.82)$ \\
\hline Clindamycin & $2(50)$ & $0(0.0)$ & $1(25)$ & $1(25)$ & $4(24.52)$ \\
\hline Gentamycin & $6(50)$ & $0(0.0)$ & $0(0.0)$ & $3(26.32)$ & $9(11.76)$ \\
\hline
\end{tabular}




\section{Discussion}

Results of prevalence and serotype distribution of L. monocytogenes in the current study are mostly similar to those in other studies. Manios et al. (2015) isolated L. monocytogenes from $28 \%$ of RTE meat samples. The contamination level of $L$. monocytogenes in roasted chicken could be linked to fecal contamination during slaughtering or contact with hands (22). The high rate of L. monocytogenes contamination in roasted chicken were demonstrated in previous studies. For example, L. monocytogenes was isolated in $6.9 \%$ of the samples (9/131) in China (23) and $24 \%$ of the samples in Turkey (5). Although other studies reported a lower prevalence of $L$. monocytogenes. For example, bacteria were detected in $5.3 \%$ of meat products in China (24), $4 \%$ in Egypt (25) and $0.7 \%$ in Estonia (26). In the current study, the prevalence of L. monocytogenes in roasted fish, roasted chicken meat and cocked beef were similar to that in Shi et al. study (23); in which, $L$. monocytogenes was recovered from $6.9 \%$ of Chinese roast chicken meats and $6.5 \%$ of Chinese cocked beef. Results were also similar to results by Fallah et al. (7), where L. monocytogenes was recovered from $4 \%$ of Iranian RTE fish products.

In this study, resistance to penicillin was the most common resistance in L. monocytogenes isolates. Issa et al. (2011) showed high levels of resistance to penicillin and ampicillin in L. monocytogenes. Other researches $(10,28,29)$ reported susceptibility of $L$. monocytogenes to ampicillin and penicillin. Ampicillin and penicillin are the most common antibiotics in listeriosis treatment $(30,31)$. The current report on L. monocytogenes sensitivity to tetracycline and gentamycin is in agreement with the report of Gomez et al. for isolates from meats and animalderived foods $(10,32)$. Reports are available on relationships between serotype distribution and antibiotic susceptibility of the $L$. monocytogenes isolates. Lemes-Marques et al. (2007) report that the human L. monocytogenes serotypes $(1 / 2 \mathrm{a}, 1 / 2 \mathrm{~b}$ and 4b) were resistant to ampicillin, vancomycin, gentamycin and trimethoprim (33). In Turkey, isolates of L. monocytogenes Serotype 1/2c were highly resistant to antibiotics, more than isolates of Serotypes $1 / 2 \mathrm{a}, 1 / 2 \mathrm{~b}$ and $4 \mathrm{~b}(34)$. The results of this study showed differences in antibiotic susceptibility of L. monocytogenes isolated from Iran. Furthermore, the results of the current serology study were similar to those of other serology studies (17-19).

\section{Conclusion}

The high rate of $L$. monocytogenes contamination in RTE meat products can be linked to the fact that these meats were not cooked thoroughly, which may cause severe health risks to consumers. Furthermore, great resistance of the L. monocytogenes isolates to antibiotics can lead to serious health problems and needs public awareness of meat producers and consumers.

\section{Financial disclosure}

The authors declare no financial interest.

\section{Funding/Support}

This study did not receive any specific grant from funding agencies in the public, commercial or not-forprofit sector.

\section{References}

1. European Food Safety Authority. The European Union summary report on trends and sources of zoonoses, zoonotic agents and food- borne outbreaks in 2016. EFSA Journal. 2017;15(12).

2. Schlech WF, Acheson D. Foodborne listeriosis. Clin Infection Diseases. 2000;31(3):770-5.

3. Kathariou S. Listeria monocytogenes virulence and pathogenicity, a food safety perspective. Journal Food Protection. 2002;65(11):1811-29.

4. Gandhi M, Chikindas ML. Listeria: A foodborne pathogen that knows how to survive. International Journal Food Microbiolgy. 2007;113(1):1-15.

5. Abay S, Irkin R, Aydin F, Mustak HK, Diker KS. The prevalence of major foodborne pathogens in ready-to-eat chicken meat samples sold in retail markets in Turkey and the molecular characterization of the recovered isolates. LWT Food Science and Technology. 2017;81:202-9.

6. Yu T, Jiang X. Prevalence and characterization of Listeria monocytogenes isolated from retail food in Henan, China. Food Control. 2014 ;37:228-31.

7. Fallah AA, Saei-Dehkordi SS, Mahzounieh M. Occurrence and antibiotic resistance profiles of Listeria monocytogenes isolated from seafood products and market and processing environments in Iran. Food Control. 2013;34(2):630-6.

8. Ayaz ND, Ayaz Y, Kaplan YZ, Dogru AK, Aksoy 
MH. Rapid detection ofListeria monocytogenes in chicken carcasses by IMS-PCR. Annual Microbiolgy. 2009;59(4):741-4.

9. Abay S, Irkin R, Aydin F, Mustak HK, Diker KS. The prevalence of major foodborne pathogens in ready-to-eat chicken meat samples sold in retail markets in Turkey and the molecular characterization of the recovered isolates. LWT Food Science and Technology. 2017;81:202-9.

10. Gomez D, Azon E, Marco N, Carraminana JJ, Rota $\mathrm{C}$, Arino A, et al. Antimicrobial resistance of Listeria monocytogenes and Listeria innocua from meat products and meat-processing environment. Food Microbiolgy. 2014;42:61-5.

11. Srinivasan V, Nam HM, Nguyen LT, Tamilselvam B, Murinda SE, Oliver SP. Prevalence of Antimicrobial Resistance Genes in Listeria monocytogenes Isolated from Dairy Farms. Foodborne Pathogen Disease. 2005;2(3):201-11.

12. Conter M, Paludi D, Zanardi E, Ghidini S, Vergara A, Ianieri A. Characterization of antimicrobial resistance of foodborne Listeria monocytogenes. Int J Food Microbiolgy. 2009;128(3):497-500.

13. ISO-11290-1: Microbiology of food and animal feeding stuffs - horizontal method for the detection and enumeration of Listeria monocytogenes-Part 1. 2017

14. Seeliger HPR, Höhne K. Chapter II Serotyping of Listeria monocytogenes and Related Species. Methods Microbiolgy. 1979;13:31-49.

15. Wieczorek K, Dmowska K, Osek J. Characterization and Antimicrobial Resistance of Listeria monocytogenes Isolated from Retail Beef Meat in Poland . Foodborne Pathogen Diseases. 2012

16. Clinical and Laboratory Standards Institute (CLSI). Methods for antimicrobial dilution and disk susceptibility testing of infrequently isolated or fastidious bacteria; approved guideline. Clin Lab Stand Inst. 2006;(26).

17. Vasilev V, Japheth R, Breuer R, Andorn N, Ben Abraham R, Yoni $\mathrm{Y}$, et al. A survey of Listeria monocytogenes strains, isolated from ready-to-eat foods in Israel over a period of 10 years, 19982007. Food Control. 2010;21(8):1179-81.

18. Wang X-M, Lu X-F, Yin L, Liu H-F, Zhang W-J, $\mathrm{Si} \mathrm{W}$, et al. Occurrence and antimicrobial susceptibility of Listeria monocytogenes isolates from retail raw foods. Food Control.
2013;32(1):153-8.

19. Kramarenko T, Roasto M, Meremäe K, Kuningas $\mathrm{M}$, Põltsama P, Elias T. Listeria monocytogenes prevalence and serotype diversity in various foods. Food Control. 2013;30(1):24-9.

20. Stonsaovapak, S., \&Boonyaratanakornkit M. Prevalence and antimicrobial resistance of Listeria species in food products in Bangkok, Thailand. Journal of Food Safety. 2010;30(1):154-61.

21. Manios SG, Grivokostopoulos NC, Bikouli VC, Doultsos DA, Zilelidou EA, Gialitaki MA, et al. A 3 -year hygiene and safety monitoring of a meat processing plant which uses raw materials of global origin. International Journal of Food Microbiolgy. 2015;209:60-9.

22. Fenlon DR, Wilson J, Donachie W. The incidence and level of Listeria monocytogenes contamination of food sources at primary production and initial processing. Journa of Applied Bacteriology. 1996;81(6):641-50.

23. Shi W, Qingping W, Jumei Z, Moutong C, Zéan Y. Prevalence, antibiotic resistance and genetic diversity of Listeria monocytogenes isolated from retail ready-to-eat foods in China. Food Control. 2015;47:340-7.

24. Wang G, Qian W, Zhang X, Wang H, Ye K, Bai Y, et al. Prevalence, genetic diversity and antimicrobial resistance of Listeria monocytogenes isolated from ready-to-eat meat products in Nanjing, China. Food Control. 2015;50:202-8.

25. Mohamed Y, Reda WW, Abdel-Moein K, Abd ElRazik KA, Barakat AMA, El Fadaly HA, et al. Prevalence and phylogenetic characterization of Listeria monocytogenes isolated from processed meat marketed in Egypt. Journal of Genetic Engireeng Biotechnoly. 2016;14(1):119-23.

26. Kramarenko $\mathrm{T}$, Roasto $\mathrm{M}$, Keto-Timonen $\mathrm{R}$, Maesaar M, Meremae $\mathrm{K}$, Kuningas $\mathrm{M}$, et al. Listeria monocytogenes in ready-to-eat vacuum and modified atmosphere packaged meat and fish products of Estonian origin at retail level. Food Control. 2016;67:48-52.

27. Issa ZM, Mohamed SAS, Muda NM, Mustakim M, Yen LH, Radu S. Antibiogram Profiles of Listeria monocytogenes isolated from foods. Vol. 7, 2nd International Conference on Biotechnology and Food Science. 2011.

28. Abdollahzadeh E, Ojagh SM, Hosseini H, Ghaemi EA, Irajian G, Naghizadeh Heidarlo M. 
Antimicrobial resistance of Listeria monocytogenes isolated from seafood and humans in Iran. Microbial Pathogens. 2016;100:70-4.

29. Chao G, Zhou X, Jiao X, Qian X, Xu L. Prevalence and Antimicrobial Resistance of Foodborne Pathogens Isolated from Food Products in China. Foodborne Pathogen Diseases. 2007;4(3):277-84.

30. Sakaridis I, Soultos N, Iossifidou E, Papa A, Ambrosiadis I, Koidis P. Prevalence and Antimicrobial Resistance of Listeria monocytogenes Isolated in Chicken Slaughterhouses in Northern Greece. Journal of Food Protection. 2011;74(6):1017-21.

31. Allen KJ, Wałecka-Zacharska E, Chen JC, Katarzyna K-P, Devlieghere F, Van Meervenne E, et al. Listeria monocytogenes - An examination of food chain factors potentially contributing to antimicrobial resistance. Food Microbioly.
2016;54(54):178-89.

32. Altuntas EG, Juneja VK, Ayhan K, Materon L, Cosansu S, Kocan D. Antibiotic and Bacteriocin Sensitivity of Listeria monocytogenes Strains Isolated from Different Foods. Food Nutrition Science. 2012;03(03):363-8.

33. Lemes-Marques EG, Cruz CD, Destro MT. Phenoand genotypic characterization of Listeria monocytogenes clinical isolates from the southwestern region of the State of São Paulo, Brazil. Brazilian Journal of Microbioly. 2007;38(2):287-92.

34. Ayaz Nd, Erol I. Relation between Serotype Distribution and Antibiotic Resistance Profiles of Listeria monocytogenes Isolated from Ground Turkey. Vol. 73, Journal of Food Protection. 